\title{
Finite Element Analysis of the Interfacial Debonding of the Galvannealed Coating Layer with High Tensile Strength Steel Substrates
}

\author{
Sohei IWAMOTO, ${ }^{1)}$ Shojiro OCHIAI ${ }^{21}$ and Hiroshi OKUDA ${ }^{21}$ \\ 1) Graduate Student, Kyoto University, Yoshida, Sakyo-ku, Kyoto 606-8501 Japan. \\ 2) Graduate School of Engineering, Kyoto University, Yoshida, Sakyo-ku, Kyoto 606-8501 Japan.
}

(Received on August 6, 2008; accepted on October 23, 2008)

\begin{abstract}
For energy saving, it is planned to use galvannealed high strength steels for the car body materials. However, the influences of the high strength steel substrate on the fracture behavior of the coating layer and interfacial debonding behavior have not been revealed yet. In the present work, numerical analysis using a finite element method was carried out. It was revealed that (i) the higher the tensile strength of the substrate, the shorter becomes the crack spacing of the coating layer and (ii) the less interfacial debonding takes place in high strength substrate steels due to the short crack spacing, as long as the coating layerand interfacial bonding-strengths of high strength substrate samples are the same as those of low strength ones.
\end{abstract}

KEY WORDS: finite element analysis; galvannealed steel; coating; cracking; spalling; interface; high tensile steel.

\section{Introduction}

The hot-dipped GA (galvannealed) steels, consisting of $\mathrm{Fe}-\mathrm{Zn}$ intermetallic coating layer and substrate steel, are widely used as architectural and car-body materials due to their high corrosion resistance and weldability. ${ }^{1,2)}$ As these materials are composed of brittle coating layer with low failure strain and ductile substrate with far higher failure strain, the coating layer exhibits multiple cracking perpendicular to the tensile direction, ${ }^{3-8)}$ followed by spalling, when tensile stress is applied externally. The spalling of the coating layer is caused by the compressive stress in the sample width direction, ${ }^{7)}$ followed by interfacial debonding. The SEM image and schematic representation of the buckling behavior of the coating layer are shown in Fig. 1.

Until now, relatively low strength steels with high formability such as interstitial free steels have been used as car body materials. In recent years, the high strength steel is counted on the car application to reduce the car weight which critically affects on the fuel economy. However, the influences of the high tensile strength steel substrate on multiple cracking- and spalling- behaviors have not been revealed yet.

In our recent works, the tensile strength of the coating layer, which is one of the major controlling factors for the multiple cracking, was estimated to be $260 \mathrm{MPa}$ commonly for IF (interstitial free steel) and SPCC (steel plate cold commercial, JIS) steel substrate samples. ${ }^{9,10)}$ Also, it was revealed that the crack spacing affects largely the subsequent spalling behavior of the coating layer. ${ }^{11}$
In the present work, the tensile strength of the coating layer and the interfacial bonding strength are common for low and high strength samples. Under such an assumption, we carried a numerical analysis using a finite element method to predict the multiple cracking- and debondingbehaviors for high strength substrate samples. It will be shown in this paper that the higher the tensile strength of the substrate, the shorter becomes the crack spacing of the coating layer and the less interfacial debonding takes place

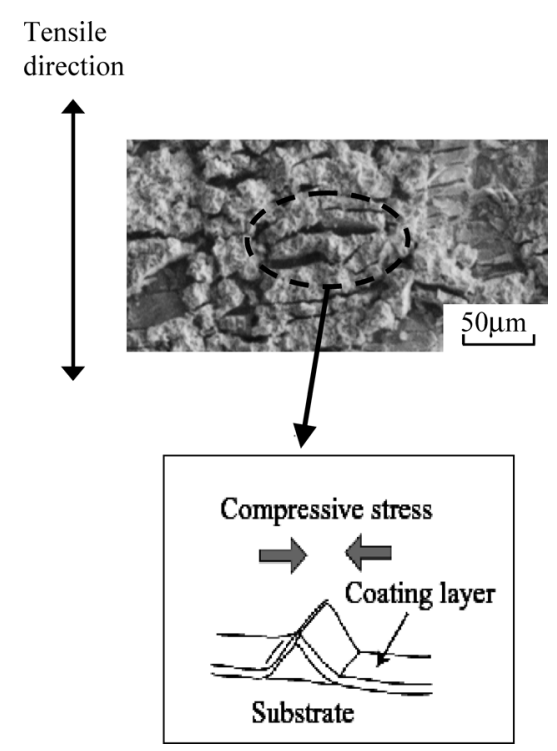

Fig. 1. SEM image and schematic representation of the buckling behavior of the coating layer. 
in high strength substrate steels due to the short crack spacing, as long as the coating layer- and interfacial bondingstrengths of high strength substrate samples are the same as those of low strength ones.

\section{Experimental Procedure}

\subsection{Samples and Input Values for Calculation}

The present study aims to reveal the influences of the substrate material on the multiple cracking and spalling. For this aim, the IF steel was taken up as an example of low strength steel for calculation. As an example of high strength steel, an imaginary high strength steel with two times yield stress and ultimate strength in comparison with that of IF steel was taken up. Hereafter, the IF and imaginary steel-based samples are noted as sample I and sample $\mathrm{H}$, respectively.

The Young's modulus, shear modulus, Poisson's ratio and coefficient of thermal expansion of the steel substrate were taken to be $210 \mathrm{GPa}^{12)} 81 \mathrm{GPa}, 0.30^{12)}$ and $2.2 \times 10^{-5} / \mathrm{K}^{13,14)}$ respectively, ${ }^{15)}$ commonly for I and $\mathrm{H}$ samples. Those of the coating layer were taken to be $140 \mathrm{GPa}^{12)} 54 \mathrm{GPa}, 0.30^{12)}$ and $1.1 \times 10^{-5} / \mathrm{K}^{13,14)}$ respectively, approximated as a single layer consisting of $\delta_{1}$ Phase $\left(\mathrm{FeZn}_{7}\right)$, as similarly as in our preceding works. ${ }^{9-11)}$ Based on the measured stress-strain curve in our preceding works, ${ }^{9,10}$ the true stress $(\sigma)$-true plastic strain $\left(\varepsilon_{\mathrm{p}}\right)$ curve of the sample I was given by

$$
\sigma=130+400 \varepsilon_{\mathrm{p}}^{0.38}
$$

The true stress $(\sigma)$-true plastic strain $\left(\varepsilon_{\mathrm{p}}\right)$ curve of the sample $\mathrm{H}$ was given by,

$$
\sigma=260+800 \varepsilon_{\mathrm{p}}^{0.38}
$$

The yielding condition for the steel substrate was given by the von Mises criterion. The stress analysis was carried out under the plane-strain condition.

\subsection{Finite Element Analysis of the Multiple Cracking}

The morphology of the specimen with multiply-cracked $\mathrm{Fe}-\mathrm{Zn}$ intermetallic compound coating layer is schematically shown in Fig. 2(a) where $L$ is the crack spacing and $T$ is the thickness of the coating layer. In the finite element analysis to calculate the stress distribution, the region ABFE was taken up as the representative. The longitudinal distance y was taken from the center plane: $y=0$ at $\mathrm{AB}$, $y=400 \mu \mathrm{m}$ at CD and $y=400 \mu \mathrm{m}+T(=10 \mu \mathrm{m}$ in the present sample) at EF. The horizontal distance $x$ was defined to be zero, at the broken end, $L / 2$ at the middle, and $L$ at the another broken end as shown in Fig. 2.

An example of the finite element mesh of the plane-symmetric model and the boundary conditions employed in the present analysis are shown in Fig. 2(b). The displacements of the cross-sections $\mathrm{ACE}$ and $\mathrm{AB}$ were taken to be zero. Common compulsory tensile displacement was given for the cross-section BDF in the $x$-direction.

For analysis of the stress distribution, the crack spacing $L=10,20,40$ and $80 \mu \mathrm{m}$ were used. As mentioned above, the present samples were heated for formation of the intermetallic compounds at $773 \mathrm{~K}$ and cooled down to room temperature. Therefore the temperature change $\Delta T=$ $-475 \mathrm{~K}$ was input. The stress of the coating layer in the $x$ -

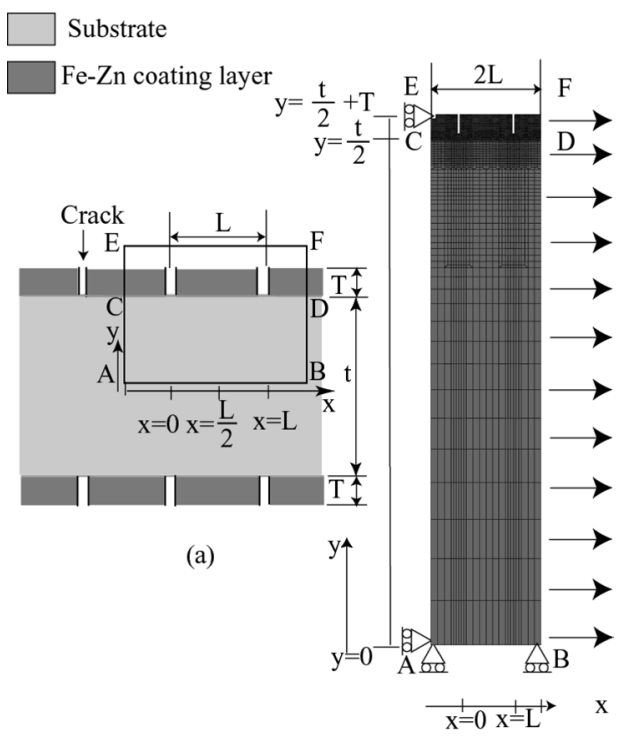

(b)

Fig. 2. FEM-mesh and boundary condition for the multiple cracking analysis.

direction, $\sigma_{x}$, was calculated for the applied tensile strain $=$ 10,20 and $30 \%$.

\subsection{Finite Element Analysis of the Interfacial Debond- ing}

3-Dimensional models for analysis of the interfacial debonding of the coating layer were prepared as follows. The morphology of the specimen with multiply cracked $\mathrm{Fe}-\mathrm{Zn}$ intermetallic compound coating layer is schematically shown in Fig. 3(a) where $L$ is the crack spacing in the tensile direction, $W$ is the crack spacing in the width direction and $T$ is the thickness of the coating layer. An example of the finite element mesh of the model employed in the present analysis is shown in Fig. 3(b). As indicated in Fig. 3(a), the longitudinal distance $x$ was taken to be zero at the middle, and to be $L / 2$ at the broken end. The distance across-the-width $y$ was taken to be zero at the broken end, to be $W / 2$ at the middle, and to be $W$ at the other broken end. The vertical distance $z$ was taken to be zero at the middle of substrate in the thickness direction. As the thickness of the substrate was $800 \mu \mathrm{m}$, the distance $z$ of the coating layer/substrate interface was taken to be $400 \mu \mathrm{m}$, and the distance $z$ was taken to be $400 \mu \mathrm{m}+T(=10 \mu \mathrm{m}$ in the present sample) at the surface of the coating layer. For the analysis of the real sample, the crack spacing in the $x$-direction $L=40 \mu \mathrm{m}$, and that in the $y$-direction $W=80 \mu \mathrm{m}$ were used, where $W=80 \mu \mathrm{m}$ corresponds to the thermally induced critical crack spacing in the coating layer, ${ }^{9,10)}$ and $L=40 \mu \mathrm{m}$ corresponds to the critical length at which buckling behavior of the coating layer were observed, as shown later in Fig. 7. The transverse isotropy of the elasto-plastic deformation and the multiple cracking behavior of the IF steel-based samples (sample I) were observed experimentally, ${ }^{18)}$ in our former work. For that of the imaginary sample, $L=40 \mu \mathrm{m}$ and $W=80 \mu \mathrm{m}$ were given for one model, and $L=20 \mu \mathrm{m}$ and $W=40 \mu \mathrm{m}$ were given for the other model which corresponded to the result of the multiple cracking analysis as will be mentioned later in Sec. 3.1. The present specimens had been heated at $773 \mathrm{~K}$ for forma- 


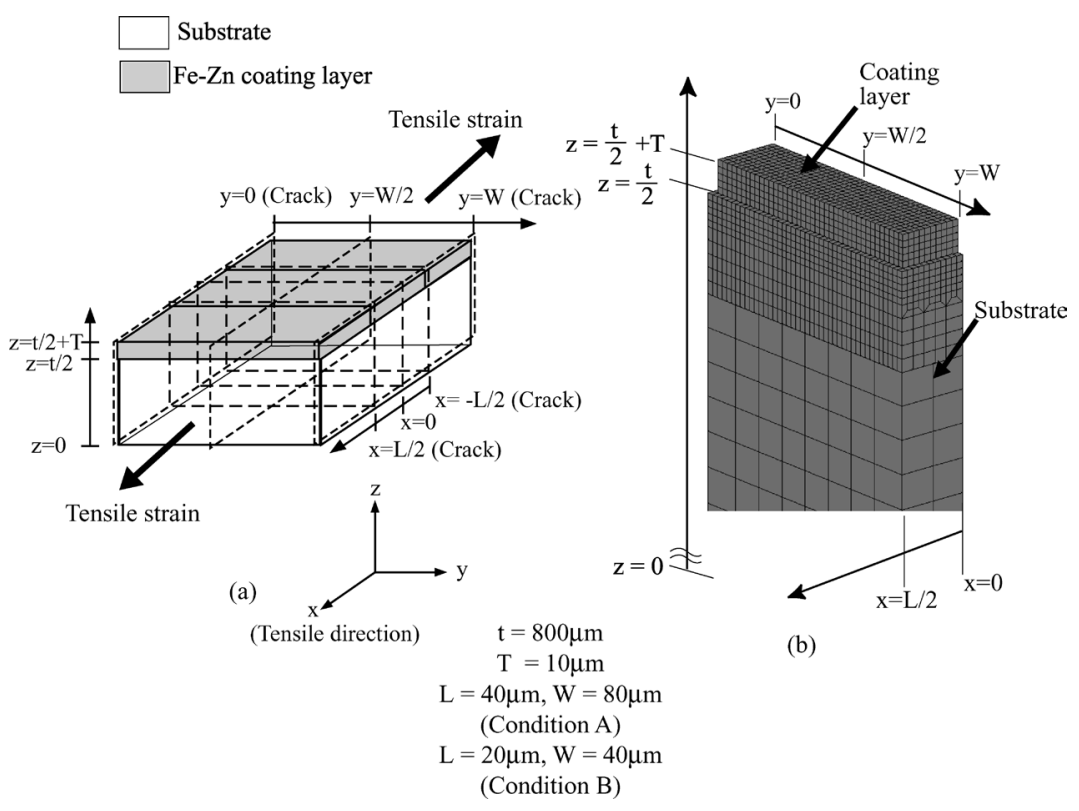

Fig. 3. FEM-mesh of the GA steel for the interfacial debonding analysis.

tion of the intermetallic compounds and cooled down to room temperature. Therefore the temperature change $\Delta T=$ $-475 \mathrm{~K}$ was input in order to incorporate the residual stress. In the calculation, the tensile strain was applied from 0 to $30 \%$ in the $x$-direction, similarly to the practical tensile test.

To describe the interfacial debonding of the brittle material with finite element method, spring elements were commonly used. As shown by our former work, the coating layer exhibits buckling before interfacial debonding. Thus tensile stress at the coating layer/substrate interface plays a dominant role for debonding. In the present work, we used spring elements which are fractured at certain stress and don't work after their fracture. The critical stress to cause the fracture of the spring elements was regarded as the interfacial debonding strength. It was taken to be $100 \mathrm{MPa}$, which could account for the experimental result fairly well.

\section{Results and Discussion}

\subsection{Finite Element Analysis of the Multiple Cracking}

The finite element analysis was carried out for both samples I and H. To describe the change of the crack spacing with applied tensile strain, first, the tensile stress distribution in the coating layer was calculated for the crack spacing $L=10,20,40$ and $80 \mu \mathrm{m}$ at the applied tensile strains 10,20 and $30 \%$ for both samples, as shown below.

The calculation results showed that the exerted stress on the coating layer increases with increasing applied tensile strain both for samples I and H. Figure 4 shows the variations of the calculated tensile stress $\sigma_{x}$ in the $x$-direction of the coating layer with distance $x$ from the crack at the applied nominal strain of $20 \%$ as an example. It is noted that the exerted stress on the coating layer of high strength steel sample is higher than that of real sample.

As shown in Fig. 4 , the $\sigma_{x}$ is highest $\left(\sigma_{x, \text { max }}\right)$ at the middle point $x=L / 2$, and the longer the crack spacing $L$, the higher becomes $\sigma_{x, \max }$. The cracking tends to occur at $L / 2$ with highest $\sigma_{x, \max }$. When the coating layer is cracked at

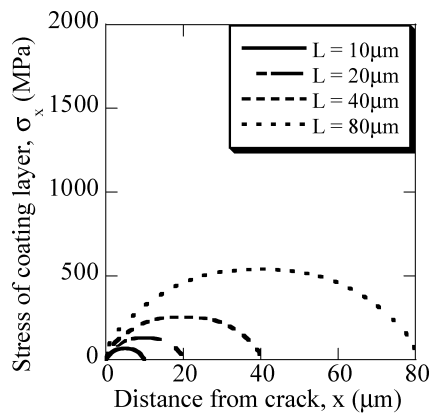

(a)

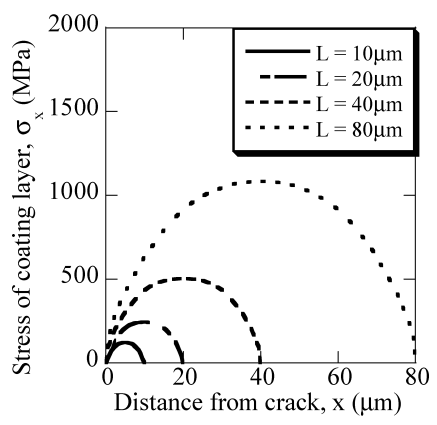

(b)

Fig. 4. Distribution of tensile stress $\sigma_{x}$ of the coating layer at the nominal strain $e=20 \%$, for sample I (a) and sample $\mathrm{H}$ (b).

$x=L / 2$, the relation between the critical length of the coating layer $L_{\mathrm{c}}$ (=the necessary length for the coating layer to be cracked) and the average crack spacing $L_{\text {ave }}$ is given by, ${ }^{17)}$

$$
L_{\mathrm{c}}=4 / 3 L_{\mathrm{av}}
$$

Figure 5 shows the relation between the calculated maximum tensile stress $\sigma_{x, \max }$ and crack spacing $L$ for sample I and sample $\mathrm{H}$. The maximum tensile stress is nearly pro- 


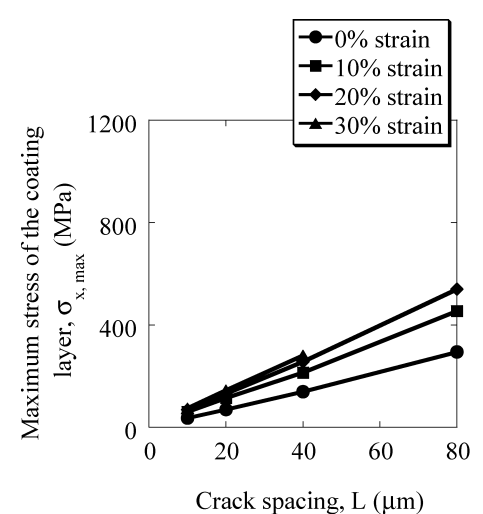

(a)

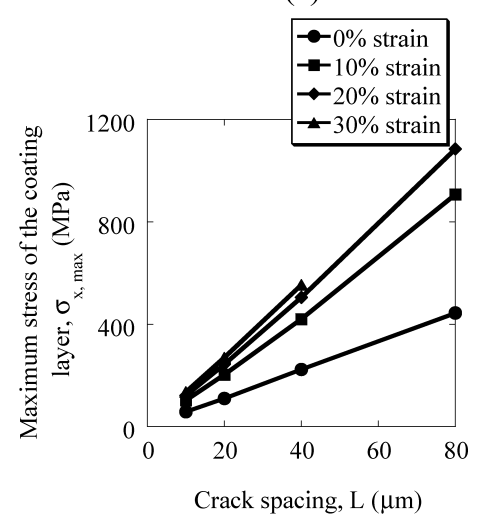

(b)

Fig. 5. The relation between the maximum tensile stress $\sigma_{x, \max }$ and crack spacing $L$ for sample I (a) and sample $\mathrm{H}(\mathrm{b})$.

portional to crack spacing at each applied strain. The slope of the linear relation between $\sigma_{x, \max }$ and $L$ in Fig. 5 corresponds to the stress transfer efficiency to the coating layer per unit length, $\sigma_{x, \max } / L .^{9-11)}$ The values of $\sigma_{x, \max } / L$ at $e=0$, 10, 20 and $30 \%$, estimated from Fig. 5, are presented in Fig. 6.

The relation of $\sigma_{x, \max } / L$ to applied strain $e$ in the applied strain range up to $30 \%$ was approximated with the following cubic function for sample I and sample $\mathrm{H}$, respectively.

$$
\begin{aligned}
\sigma_{x, \max } / L=3.63+25.5 e-61 e^{2}+47 e^{3} & (\text { Sample I }) . . . \\
\sigma_{x, \max } / L=5.55+77.9 e-250 e^{2}+270 e^{3} & (\text { Sample H }) \ldots .
\end{aligned}
$$

The strength of the coating layer $\sigma_{\mathrm{c}, \text { UTS }}$ has been estimated to be around $260 \mathrm{MPa}^{9,10)}$ in our former work for IFand SPCC substrate samples. The critical crack spacing $L_{\mathrm{c}}$ was calculated by setting $L=L_{\mathrm{c}}$ and $\sigma_{x, \max }=260 \mathrm{MPa}$ and $e$ into Eqs. (4) and (5) for sample I and sample H, respectively. Figure 7 shows the calculated change of the critical crack spacing of the coating layer $L_{\mathrm{c}}$ with nominal strain for $\sigma_{\mathrm{c}, \mathrm{UTS}}=260 \pm 30 \mathrm{MPa}$. For reference, the measured $L_{\mathrm{c}}-e$ relation sample I, which is well described by $\sigma_{\mathrm{c}, \mathrm{UTS}}=$ $260 \pm 30 \mathrm{MPa}$, is presented in Fig. 7. For the same coating layer strength $\left(\sigma_{\mathrm{c}, \text { UTS }}=260 \mathrm{MPa}\right)$, the change of crack spacing with applied nominal strain is estimated for sample $\mathrm{H}$, as shown in Fig. 7.

As shown in Fig. 7, the critical length of the coating layer of sample $\mathrm{H}$ is almost a half as long as that of sample I. As

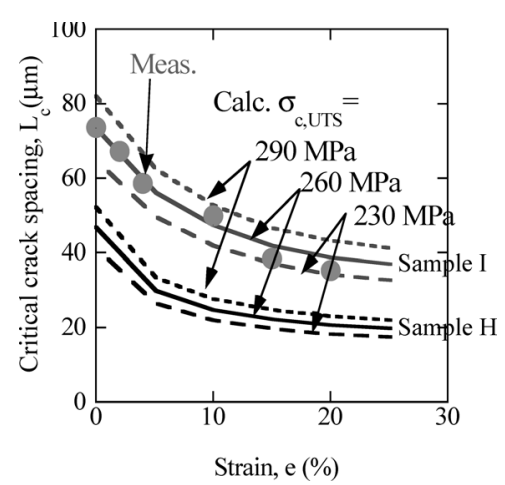

Fig. 7. Change of the crack spacing of the coating layer with nominal strain for $\sigma_{\mathrm{c}, \mathrm{UTS}}=$ $260 \pm 30 \mathrm{MPa}$ together with the experimental result for the sample I.

has been shown in our preceding works, ${ }^{9-11)}$ the critical crack spacing values of sample at $0 \%$ (=the thermally induced critical crack spacing) and at or higher than $20 \%$ (=the strain at which interfacial debonding occurs) were about $80 \mu \mathrm{m}$ and $40 \mu \mathrm{m}$, respectively. In contrast, those of sample $\mathrm{H}$ at the former and latter strains were about $40 \mu \mathrm{m}$ and $20 \mu \mathrm{m}$, respectively.

\subsection{Finite Element Analysis of the Interfacial Debond- ing}

From the results of the multiple cracking analysis, the crack spacing values ( $L$ in the tensile direction and $\mathrm{W}$ in the width direction in Fig. 3) for calculation of the interfacial debonding behavior were given as follows. In both samples $\mathrm{I}$ and $\mathrm{H}$, the tensile strain was applied in one direction. Before the application of tensile strain, the crack spacings in the coating layer were 80 and $40 \mu \mathrm{m}$ for the samples I and $\mathrm{H}$, respectively, as stated in Sec. 3.1. The experimentally measured applied strain at which the spalling of the coating layer occurred in sample I was around $20 \%$ or slightly higher than $20 \%$. At these strain, the crack spacing values in the coating layer were 40 and $20 \mu \mathrm{m}$ for the samples I and $\mathrm{H}$, respectively, as stated also in Sec. 3.1. Based on these results, the crack spacing values in the tensile direction $L$ and that in the width direction $W$ (Fig. 3) were given by 40 and $80 \mu \mathrm{m}$, respectively, for calculation of the debonding behavior of the sample I. The geometrical condition of $L=40$ and $W=80 \mu \mathrm{m}$ for calculation of interfacial debonding behavior is hereafter noted as the condition $\mathrm{A}$ for simplicity.

Due to the same reason, the values of $L$ and $W$ (Fig. 3) at which interfacial debonding takes place in the sample $\mathrm{H}$ are given by 20 and $40 \mu \mathrm{m}$, respectively. The geometrical condition of $L=20$ and $W=40 \mu \mathrm{m}$ for calculation of interfacial debonding behavior is hereafter noted as the condition $\mathrm{B}$ for simplicity.

In the calculation in this work, the conditions A and B were used for analysis of interfacial debonding in the samples $\mathrm{I}$ and $\mathrm{H}$, respectively. In addition, for reference, the condition A was used also for the analysis of the sample $\mathrm{H}$, with which the influence of substrate material on the debonding behavior under the same geometrical condition was revealed as shown below. 


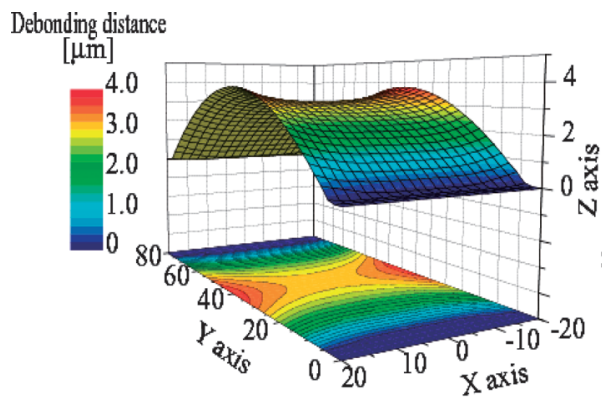

(a)

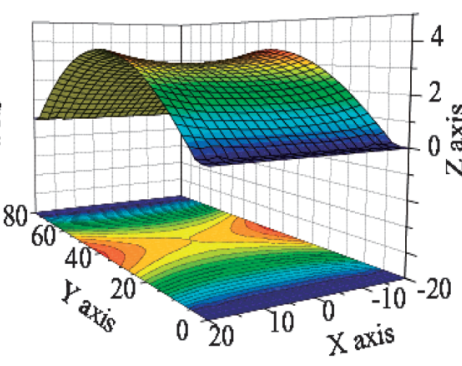

(b)

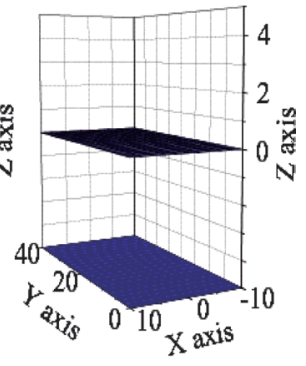

(c)

Fig. 8. Calculated distributions of the interfacial debonding distance from substrate to coating layer at $20 \%$ tensile strain in the $x$-direction in (a) sample I (condition A), (b) sample H (condition A) and (c) sample H (condition B).

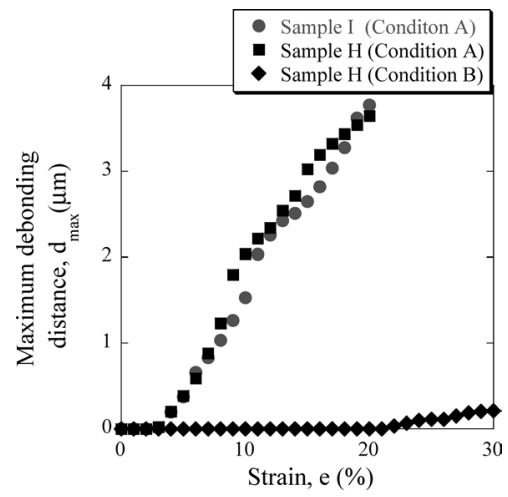

Fig. 9. Calculated change of the maximum debonding distance $d_{\max }$ with applied tensile strain $e$ for the samples I (condition $\mathrm{A}$ ) and $\mathrm{H}$ (conditions $\mathrm{A}$ and $\mathrm{B}$ ).

Figure 8 shows the variations of the distribution of the interfacial debonding distance from substrate to coating layer. The $x$-, $y$ - and $z$-axes in Fig. 8 show the coordinates indicated in the coating layer (Fig. 3). The distribution of the interfacial debonding distance from the substrate to coating layer in the $z$-direction is shown with color. The debonding distance from substrate to coating layer was maximum at $x=L / 2$ and $y=W / 2$ for all calculation results. Figure 9 shows the change of the maximum debonding distance $d_{\max }$ with applied tensile strain $e$ for sample I (condition $\mathrm{A}$ ) and sample $\mathrm{H}$ (condition $\mathrm{A}$ and $\mathrm{B}$ ).

As shown in Fig. 8 and Fig. 9, the debonding distances of samples I and $\mathrm{H}$ are not so much different under the condition A ( $L=40$ and $W=80 \mu \mathrm{m})$. It revealed that the strengthening of the substrate itself does not give a big influence on the debonding behavior. On the other hand, the debonding distance in the sample $\mathrm{H}$ under the condition $\mathrm{B}$, which refers to the actual behavior due to the preceding progress of the multiple cracking of the coating layer, is definitely short in comparison with that of samples I and $\mathrm{H}$ under the condition A. This result evidently shows that the replacement of the high strength substrate for the low one acts to reduce the interfacial debonding through the enhancement of multiple cracking, if the tensile strength of the coating layer and interfacial bonding strength that have been actually obtained for the low strength steel (IF and SPCC) substrates, are retained for the high strength substrate.

\section{Conclusions}

The influences of the high tensile strength steel substrate on the multiple cracking and spalling was studied by the finite element stress analysis. It was revealed that the replacement of the high strength substrate for the low one acts to enhance the multiple cracking and to reduce the interfacial debonding through the enhancement of multiple cracking, if the tensile strength of the coating layer and interfacial bonding strength are retained on the level of those for the low strength steel (IF and SPCC).

\section{Acknowledgement}

The authors wish to express their gratitude to Japan Society for the Promotion of Science for Young Scientists and to The Iron and Steel Institute of Japan for the support of the present work.

\section{REFERENCES}

1) C. E. Jordan CE, K. M. Goggins and A. R. Marder: Metall. Mater. Trans. A, 25A (1994), 2101.

2) S. Lazik, C. Esling and J. Wegria: Textures Microst., 23 (1995), 131.

3) A. Kelly A and W. R. Tyson: J. Mech. Phys. Solids, 13 (1965), 329.

4) S. Ochiai and K. Osamura: J. Mater. Sci., 21 (1986), 2735.

5) M. S. Hu and A. G. Evans: Acta Metall., 37 (1989), 917.

6) Y. Leterrier, L. Boogh, J. Andersons and J.-A. E. Mason: J. Polym. Sci. B, Polym. Phys., 35 (1997), 1449.

7) S. Ochiai and Y. Murakami: Met. Sci., 41 (1976), 401.

8) J. Andersons, U. A. Handge, I. M. Sokolov and B. Blumen: Eur. Phys. J., B17 (2000), 261.

9) S. Ochiai, S. Iwamoto, T. Tomida, T. Nakamura, H. Okuda, M. Tanaka and H. Hojo: Metall. Mater. Trans. A, 36A (2005), 1807.

10) S. Iwamoto, S. Ochiai, T. Nakamura and H. Okuda: Tetsu-toHagané, 91 (2005), 335.

11) S. Iwamoto, S. Ochiai, H. Okuda and T. Inoue: ISIJ Int., 47 (2007), 930.

12) G. Reumont, J. B. Vogt, A. Iost and J. Foct: Surf. Coat. Technol., 139 (2001), 265.

13) J. Foct: Scr. Metall. Mater, 28 (1993), 127.

14) A. Iost and J. Foct: J. Mater. Sci., 12 (1993), 1340.

15) E. Tzimas and G. Papadrimitriou: Surf. Coat. Technol., 145 (2001), 176.

16) A. T. Alpas and J. Inagaki: ISIJ Int., 40 (2000), 172.

17) T. Osawa, A. Nakayama, M. Miwa and A. Hasegawa: J. Appl. Polym. Sci., 22 (1978), 3203.

18) T. Nakamura, S. Ochiai, S. Iwamoto and H. Okuda: Tetsu-toHagané, 91 (2005), 342. 